INFLAMMATORY BOWEL DISEASE

\title{
Magnetic resonance colonography for the detection of inflammatory diseases of the large bowel: quantifying the inflammatory activity
}

\author{
W M Ajaj, T C Lauenstein, G Pelster, G Gerken, S G Ruehm, J F Debatin, S C Goehde
}

Gut 2005;54:257-263. doi: 10.1136/gut.2003.037085

See end of article for authors' affiliations

Correspondence to:

Dr W M Ajaj, Department of Diagnostic and Interventional Radiology, University Hospital Essen, Hufelandstr 55, Essen 45122, Germany;

waleed.ajaj@

uni-essen.de

Revised version received 24 March 2004

Accepted for publication

30 March 2004
Introduction: The purpose of this study was to assess the diagnostic accuracy of magnetic resonance colonography (MRC) for its ability to detect and quantify inflammatory bowel disease (IBD) affecting the colon. Endoscopically obtained histopathology specimens were used as the standard of reference.

Materials and methods: Fifteen normal subjects and 23 patients with suspected IBD of the large bowel underwent MRC. Three dimensional T1 weighted data sets were collected following rectal administration of water prior to and 75 seconds after intravenous administration of paramagnetic contrast (gadoliniumBOPTA). The presence of inflammatory changes in patients was documented based on bowel wall contrast enhancement, bowel wall thickness, presence of perifocal lymph nodes, and loss of haustral folds. All four criteria were quantified relative to data obtained from normal subjects and summarised in a single score. This MRC based score was compared with histopathological data based on conventional endoscopic findings.

Results: MRC correctly identified 68 of 73 segments found to reveal IBD changes by histopathology. All severely inflamed segments were correctly identified as such and there were no false positive findings. Based on the proposed composite score, MRC detected and characterised clinically relevant IBD of the large bowel with sensitivity and specificity values of $87 \%$ and $100 \%$, respectively, for all investigated colonic segments.

Conclusion: MRC may be considered a promising alternative to endoscopic biopsy in monitoring IBD activity or assessing therapeutic effectiveness.
E ndoscopic biopsy is considered the gold standard for the detection and quantification of inflammatory bowel diseases (IBD)..$^{1-3}$ Invasiveness, procedure related discomfort, risk of perforation, and poor patient acceptance have driven the exploration for alternatives to endoscopy for diagnosing and characterising $\mathrm{IBD}^{4-8}$ Thus the use of fluoroscopy, leucocyte scintigraphy, and computed tomography (CT) for these purposes have been well described..$^{9-15}$ Beyond lack of diagnostic accuracy, exposure to ionising radiation casts a shadow over the future of all three alternatives as a primary means of gauging IBD, particularly in view of the young age of the patients. ${ }^{16}{ }^{17}$ Hence efforts have focussed on magnetic resonance imaging (MRI).

A number of studies have reported on the ability of MRI to detect IBD. Most protocols relied on administration of paramagnetic contrast to assess bowel wall enhancement on Tl weighted images. ${ }^{18} 19$ While excellent image quality with clear delineation of diseased bowel regions was achieved, correlation with the Crohn's disease activity index has been poor. ${ }^{20-25}$

Recently, MR colonography (MRC) based on the acquisition of Tl weighted three dimensional data sets following colonic distension with a water enema and administration of paramagnetic contrast has been described. ${ }^{26-28}$ The technique is successful in detecting colorectal masses beyond $5 \mathrm{~mm}$ in size. Reflecting its non-invasive character, sparing the patient from any exposure to ionising radiation, MRC is preferred over conventional endoscopy by the majority of patients. ${ }^{29} 30$

This study was designed to assess the diagnostic accuracy of MRC for its ability to detect and quantify IBD affecting the large bowel, using endoscopically obtained histopathology specimens as the gold standard.

\section{MATERIAL AND METHODS}

The study was conducted in accordance with all guidelines set forth by the approving institutional review board. Written informed consent was obtained prior to each examination. Exclusion criteria included contraindications to MRI, such as presence of a pacemaker, metallic implants in the central nervous system, or claustrophobia.

\section{Subjects}

To evaluate normal colonic parameters, MRC was initially performed on 15 healthy volunteers (nine women, six men; aged 35-50 years (mean age 43 years)) with no history of IBD. Over a three month period, MRC was subsequently performed on 23 patients (14 women, nine men; aged 2760 years (mean age 37.2 years)). All patients had been referred for conventional colonoscopy because of known IBD (ulcerative colitis $n=16$, Crohn's disease $n=7$ ) affecting the large bowel. Apart from clinical suspicion, all patients exhibited high inflammatory parameters (leucocytosis $>13000 / \mathrm{nl}$ and/or $\mathrm{C}$ reactive protein $>1.5 \mathrm{mg} / \mathrm{dl}$ ) and clinical symptoms such as abdominal pain, pararectal bleeding, fever, or diarrhoea.

\section{MRI}

Following standard bowel cleansing (oral ingestion of $3000 \mathrm{ml}$ Golytely; Braintree Laboratories, Braintree, Massachusetts, USA) all MR examinations were performed

\footnotetext{
Abbreviations: $M R$, magnetic resonance; $M R I$, magnetic resonance imaging; $M R C$, magnetic resonance colonography; $I B D$, inflammatory bowel disease; CT, computed tomography; CTC, computed tomography colonography; VIBE, volumetric interpolated breathhold examination; SI, signal intensity; CNR, contrast to noise ratio
} 
on a 1.5 T MR system (Magnetom Sonata, Siemens Medical Solutions, Erlangen, Germany) in the prone position. A combination of two surface coils was used in conjunction with the built-in spine array coil for signal reception to permit coverage of the entire colon. To minimise bowel peristalsis, $40 \mathrm{mg}$ of scopolamine (Buscopan; Boehringer Ingelheim, Germany) were injected intravenously prior to rectal filling. Following placement of a rectal enema tube (E-Z-Em; Westbury, New York, USA), the colon was filled with 1500-2000 ml of warm water using hydrostatic pressure (1-1.5 m water column). The filling process was monitored with a real time fluoroscopic sequence in coronal plane (TR/TE $2.4 / 1.2 \mathrm{~ms}$, flip angle $60^{\circ}$, field of view $400 \times 350 \mathrm{~mm}$, matrix $205 \times 256$, and a slice thickness of $5 \mathrm{~mm}$ ) permitting the acquisition of one image per second. The filling process was stopped as soon as colonic distension to the level of the caecum was verified on MR fluoroscopy.

With the colon adequately distended, a Tl weighted three dimensional gradient echo data set with integrated fat suppression (volumetric interpolated breathhold examination (VIBE)) was collected in the coronal plane. Sequence parameters included: TR/TE 3.1/1.1 ms, flip angle $12^{\circ}$, field of view $450 \times 450 \mathrm{~mm}$, matrix $168 \times 256$, and an effective slice thickness of $1.6 \mathrm{~mm}$. Subsequently, paramagnetic contrast (Gadolinium-BOPTA, Multihance; Bracco, Italy) was administered intravenously at a dosage of $0.2 \mathrm{mmol} / \mathrm{kg}$ and a flow rate of $3.5 \mathrm{ml} / \mathrm{s}$. Following a delay of $75 \mathrm{~s}$, the three dimensional acquisition was repeated with identical imaging parameters. The three dimensional data were collected breathheld over 22 seconds.

\section{Conventional colonoscopy}

Conventional colonoscopy was performed using standard equipment (model CFQ 140; Olympus, Tokyo, Japan) within 24 hours of the MR examination. The attending gastroenterologist was unaware of the MR findings. When necessary, sedatives (Dormicum; Roche, Germany) or analgesics (Dolantin; Hoechst, Germany) were administered. Suspicious inflammatory segments were recorded and biopsied. All biopsy materials were analysed by a histopathologist who graded the specimen as follows: normal, slight inflammation, moderate inflammation, or severe inflammation.

\section{Data analysis}

For each subject, both native and contrast enhanced three dimensional MRI data sets were transferred to a post processing workstation (Virtuoso; Siemens Medical Solutions, Erlangen, Germany). The data sets were assessed in a consensus mode by two experienced radiologists in the multiplanar reformation mode, which permitted scrolling through the three dimensional data sets in all three orthogonal planes. For analysis, the colon was divided into six segments: rectum, sigmoid colon, descending colon, transverse colon, ascending colon, and caecum.

MRC quality was assessed qualitatively for both volunteers and patients. Colonic distension was classified for each segment as: $1=$ well distended, 2 = moderately distended, and $3=$ poorly distended. Furthermore, each segment was evaluated for the presence of artefacts: $1=$ no artefacts; $2=$ moderate artefacts, diagnostic image quality; and 3 = extensive artefacts, non-diagnostic image quality.

Analysis of the volunteer data was conducted to serve as a reference base. Signal intensity (SI) measurements were performed within regions of interest placed in the lumen and adjacent wall of all colonic segments for all 15 normal subjects. For this purpose, coronal MR images were magnified threefold. Image noise, defined as the standard deviation of SIs measured in a region of interest outside the body, was also determined. Based on these measurements, contrast to noise ratios (CNR) were calculated for representative parts of all bowel segments on the pre and contrast enhanced data sets: $\mathrm{CNR}=(\mathrm{SI}$ (colonic wall) $-\mathrm{SI}$ (lumen))/noise. Furthermore, the number of haustral folds
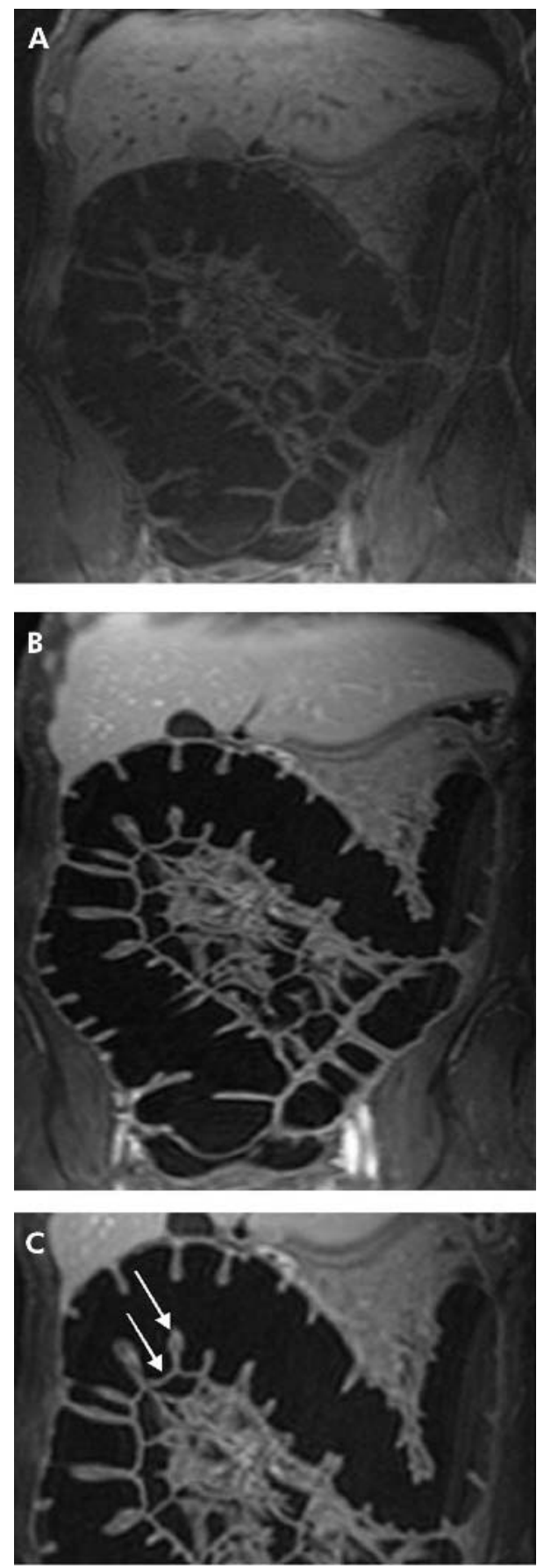

Figure 1 (A) A 38 year old volunteer undergoing magnetic resonance colonography in conjunction with rectal application of water. The coronal source image of $\mathrm{Tl}$ weighted three dimensional GRE (TR/TE $3.1 / 1.1$ ) scan acquired prior to intravenous application of contrast medium shows moderate contrast between bowel wall and bowel lumen. (B) Coronal source images of the same volunteer acquired 75 seconds after intravenous administration of gadolinium. The colonic wall enhances brightly and can be easily delineated against the background of a dark water filled colonic lumen. (C) Transverse colon of the same volunteer. The colonic wall shows a normal thickness (2 mm) (arrow), contrast uptake (contrast to noise ratio 42), and number of haustral folds (14) (arrow). 
Table 1 Mean clinical data for the 15 volunteers, regarding image quality and inflammatory criteria

\begin{tabular}{|c|c|c|c|c|c|c|c|}
\hline Segment & Rectum & $\begin{array}{l}\text { Sigmoid } \\
\text { colon }\end{array}$ & $\begin{array}{l}\text { Descending } \\
\text { colon }\end{array}$ & $\begin{array}{l}\text { Transverse } \\
\text { colon }\end{array}$ & $\begin{array}{l}\text { Descending } \\
\text { colon }\end{array}$ & Caecum & Average \\
\hline Distension & $1.17(0.4)$ & $1.31(0.5)$ & $1.22(0.4)$ & $1.20(0.3)$ & $1.21(0.4)$ & $1.21(0.4)$ & 1.22 \\
\hline Artefacts & $1.14(0.2)$ & $1.26(0.4)$ & $1.28(0.5)$ & $1.25(0.3)$ & $1.27(0.5)$ & $1.25(0.5)$ & 1.24 \\
\hline CNR pre contrast & 14.0 (3) & $13.0(4)$ & $13.0(4)$ & $14.0(3)$ & $12.0(3)$ & $12.0(3)$ & 13.0 \\
\hline CNR post contrast & $43.0(4)$ & $37.0(3)$ & $23.0(3)$ & 40.0 (4) & $21.0(4)$ & $25.0(3)$ & 31.5 \\
\hline Wall thickness $(\mathrm{mm})$ & $2.20(0.2)$ & $2.10(0.1)$ & $2.10(0.1)$ & $2.10(0.1)$ & $2.00(0.1)$ & $1.90(0.2)$ & 2.0 \\
\hline Perifocal lymph nodes ( $\mathrm{n}$ ) & 0 & 0 & 0 & 0 & 0 & 0 & 0 \\
\hline Haustral folds ( $\mathrm{n}$ ) & $2.5(0.5)$ & $12.0(2)$ & $14.0(4)$ & $16.0(2)$ & $11.0(3)$ & $7.0(2)$ & 10.4 \\
\hline
\end{tabular}

Distension and the presences of artefacts was ranked according to a three point scale $(1=$ good distension, no artefacts and $3=$ poor distension, extensive artefacts).

CNR, contrast to noise ratio.

as well as colonic wall thickness were determined for all colonic segments.

Patient MR data sets were assessed for the presence of IBD. Criteria included increased contrast uptake in the colonic wall, bowel wall thickening, number of lymph nodes, and loss of haustral folds. Assessment of these parameters was expressed relative to measurements determined in normal subjects. Thus contrast uptake in patients was graded as: $0=$ no increased uptake; $1=$ less than $25 \%$ increase; $2=25$ $50 \%$ increase; and $3=$ more than $50 \%$ increase in contrast uptake compared with the standard of reference determined in the volunteer cohort. Thickness of the colonic wall was graded as: $0=$ no bowel wall thickening; $1=$ less than $25 \%$ increase; $2=25-50 \%$ increase; and $3=$ more than $50 \%$ increase in bowel wall thickening. The number of colonic folds in each segment was documented and characterised relative to the reference parameters determined in normal subjects: $0=$ no loss of haustration; $1=$ loss of haustral folds less than 25\%; $2=$ loss of haustral folds of $25-50 \%$; and $3=$ loss of haustral folds more than $50 \%$. Furthermore, patient images were assessed for the presence of perifocal lymph nodes. Their presence was deemed pathological and hence graded as follows: $0=$ no lymph nodes; $1=1-4$ lymph nodes; $2=5-10$ lymph nodes; and $3=$ more than 10 lymph nodes.

For each abnormal segment identified in the 23 examined patients, an inflammatory score, based on the sum of the four outlined inflammatory parameters, was determined. It was classified as follows: $\leqslant 4$ points $=$ slight inflammation; $5-8$ points $=$ moderate inflammation; and $>8$ points $=$ severe inflammation. The accuracy of the inflammatory scores determined by MRC were assessed by calculating point estimates for sensitivity and specificity using the histopathology data as the standard of reference.

\section{RESULTS}

All MR examinations in normal subjects and patients were completed without complications. Similarly, there were no complications associated with conventional colonoscopy or endoscopic biopsy.

\section{MR findings}

MRC image quality was rated as "diagnostic" in all normal subjects and patients. The mean artefact value was 1.24 for normal subjects and 1.40 for patients. Concerning the presence of artefacts, in normal subjects the best image quality was found in the rectum with a mean value of 1.14 (patients 1.23) and the poorest results were seen in the descending and ascending colon with average values of 1.28 and 1.27, respectively (patients 1.30 and 1.31, respectively). Artefacts were mainly related to motion or wrap around. The mean distension value in normal subjects was 1.22. Best results were documented in segments 1 and 4, with mean values of 1.17 and 1.20 (patients 1.20 and 1.29). Distension
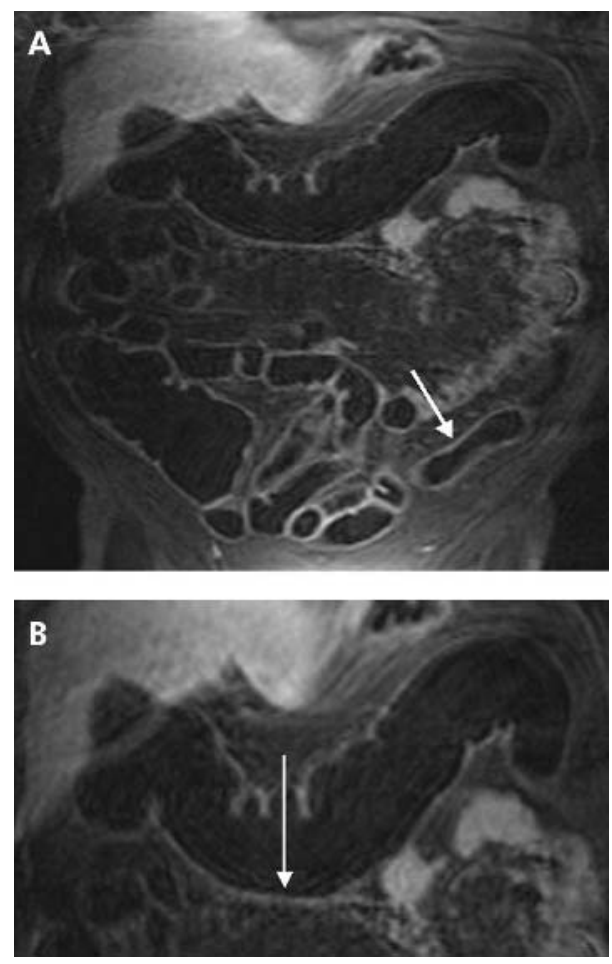

Figure 2 (A) T1 weighted three dimensional GRE image (TR/TE 3.1/ 1.1) of a 55 year old male patient with known Crohn's disease. Magnetic resonance colonography (MRC) visualised a slight

inflammation in the descending colon based on an increase in contrast uptake and wall thickness and decrease in the number of haustral folds (arrow). This finding was confirmed by histopathology. (B) Detailed display of the transverse colon of the same patient. By means of MRC, the transverse colon was graded as normal (arrow). However,

histopathology showed slight inflammation in the transverse colon.

was poorest in segment 2 with a mean value of 1.31 (patients 1.42 ).

In normal subjects, the mean CNR value after intravenous injection of paramagnetic contrast agent was highest in the rectum (43.0) and lowest in the ascending colon (21.0). Mean colonic wall thickness was $2 \mathrm{~mm}$ and there were no statistically significant differences between all colonic segments (fig $1 \mathrm{~A}-\mathrm{C}$ ). No perifocal lymph nodes were observed in any of the volunteers. The number of haustral folds was highest in the transverse colon $(n=16)$ and lowest in the rectum $(n=2.5)$. Detailed data for all segments and volunteers are listed in table 1.

\section{Conventional colonoscopy and histopathology}

In conventional colonoscopy, 92 of 138 segments contained within the 23 patients were considered diseased and thus 

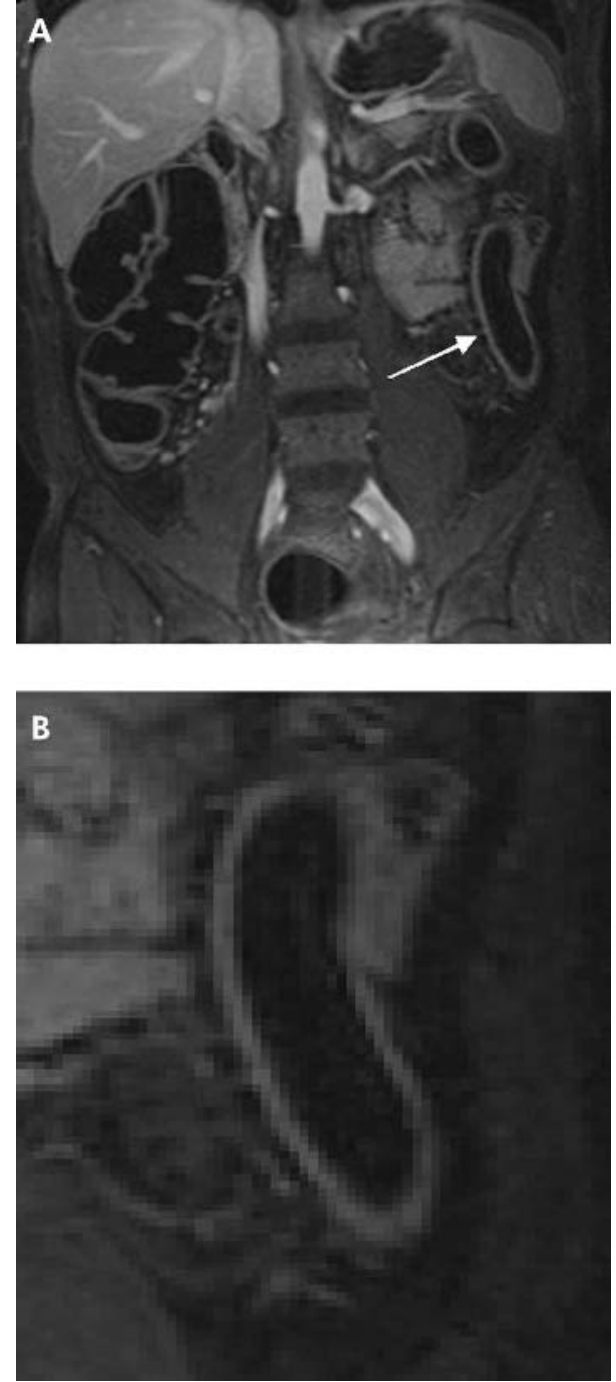

Figure 3 (A) T1 weighted three dimensional GRE image (TR/TE 3.1/ 1.1) of a 47 year old male patient with known ulcerative colitis. Magnetic resonance colonography diagnosed an inflammation in the descending colon (arrow). (B) Detailed display of the descending colon of the same patient which displays loss of haustral markings and slight bowel wall thickening. Due to the absence of lymph nodes as well as normal contrast uptake in the colonic wall, inflammation was rated as slight. This was confirmed by subsequent endoscopy.

subjected to biopsy. The segmental distribution was as follows: rectum 1: 14 biopsies; sigmoid colon: 18 biopsies; descending colon: 18 biopsies; transverse colon: 20 biopsies; ascending colon 5: 12 biopsies; and caecum: 10 biopsies. Histopathological analysis documented the presence of inflammatory changes in 73 segments: rectum: $n=11$; sigmoid colon: $n=16$; descending colon: $n=13$; transverse colon: $\mathrm{n}=15$; ascending colon: $\mathrm{n}=8$; and caecum: $\mathrm{n}=10$. The pathologist graded the affected segments as follows: slight inflammation $(\mathrm{n}=31)$, moderate inflammation $(n=25)$, and severe inflammation $(n=17)$.

\section{Comparison of MRC and histopathology}

Similar to conventional colonoscopy and histopathology, MRC correctly diagnosed colonic segments affected by IBD in all 23 patients. MRC correctly identified 68 of 73 histopathology proven diseased segments. Five segments considered inflamed by histopathology were considered normal on MRI. These included three segments with slight
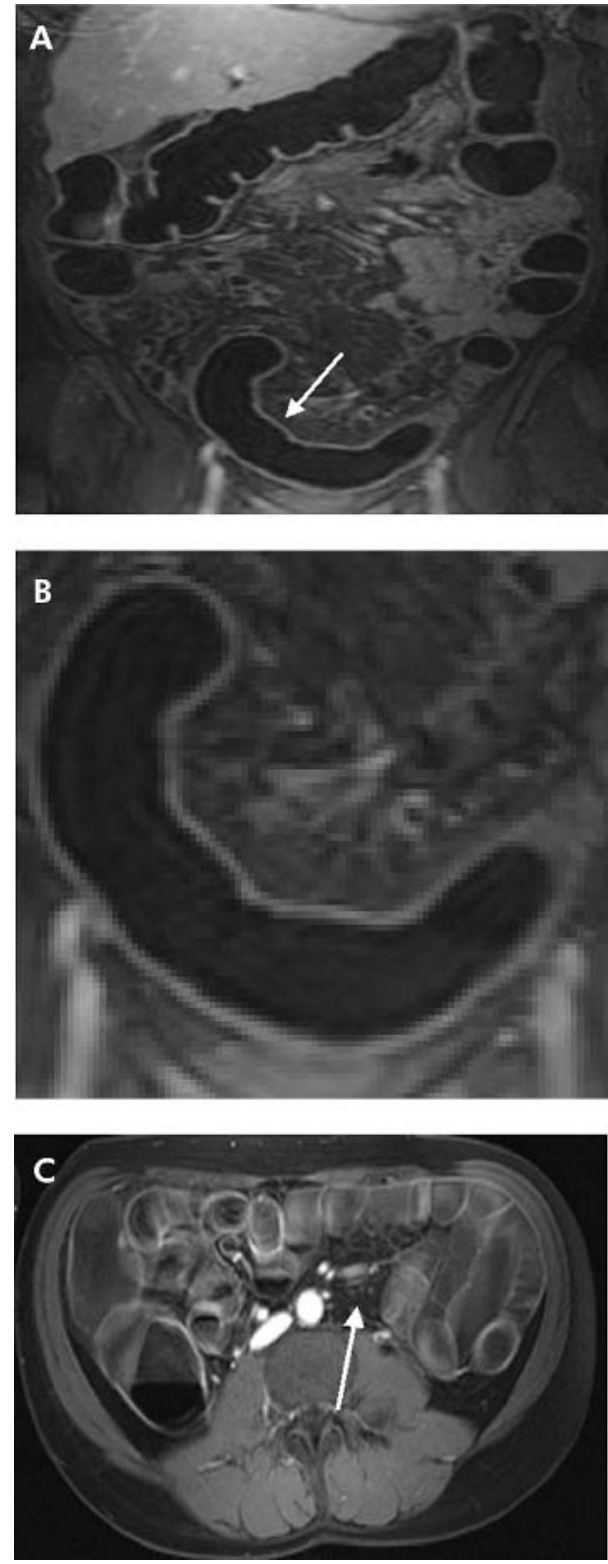

Figure 4 (A) T1 weighted three dimensional GRE image (TR/TE 3.1/ 1.1) of 31 year old male patient with known Crohn's disease. An inflammatory process was detected in the rectum and sigmoid colon (arrow). (B) Detailed display of (A). Loss of haustral markings and increased contrast uptake of the colonic wall as well as bowel wall thickening were determined leading to a diagnosis of inflammation. (C) On the axial reformatted image, several mesenteric lymph nodes were found (arrow). Subsequent endoscopy and biopsy confirmed the presence of an acute moderate inflammation of the sigmoid colon.

inflammation (transverse colon in two patients and caecum in one patient) and two segments in which histopathology revealed moderate inflammation (rectum and transverse colon in two patients) (fig 2A, B). There were no false positive readings based on the MR data sets. Similarly, characterisation of inflammatory disease proved correct in all 68 segments considered diseased on MRI: slight inflammation ( $\leqslant 4$ points) in 28 segments (histopathology 31 ) (fig 3AB), moderate inflammation (5-8 points) in 23 segments (histopathology 25) (fig 4A-C), and severe inflammation (>8 points) in 17 segments (histopathology 17) (fig 5A-D). Based on the proposed composite score, MRC detected and characterised clinically relevant IBD of the large bowel with 

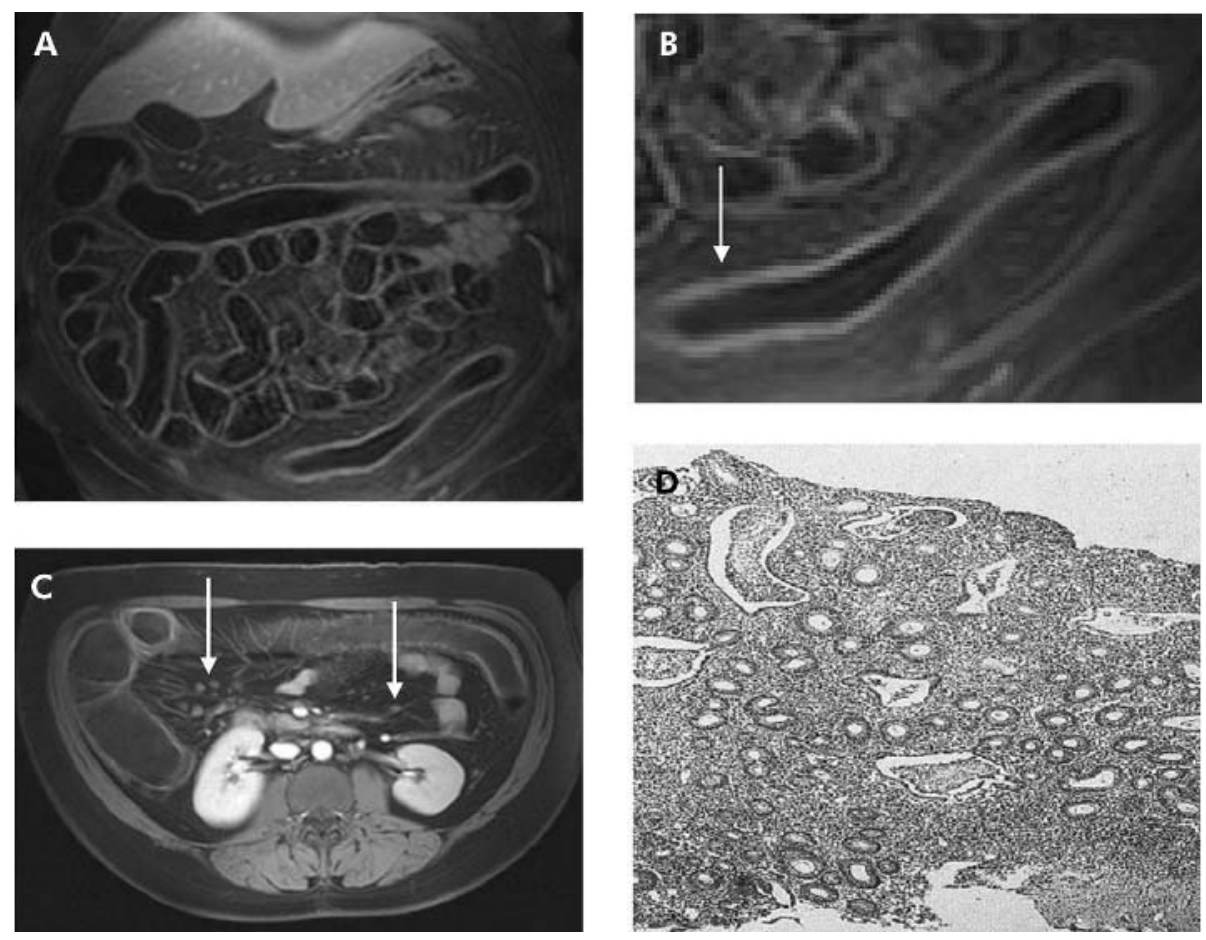

Figure 5 (A) T1 weighted three dimensional GRE image (TR/TE 3.1/1.1) of a 39 year old female patient with known ulcerative colitis. (B) Detailed display of the descending colon of (A). Complete loss of haustral markings, increased contrast uptake of the colonic wall, as well as bowel wall thickening were determined (arrow). (C) Axial reformatted T1 weighted image of the same patient. Multiple mesenteric lymph nodes were found (arrows). (D) Histopathology of the descending colon confirmed the diagnosis of an acute severe ulcerative colitis showing loss of haustral fold, multiple crypt abscesses, and infiltration with granulocytes.

sensitivity and specificity values of $87 \%$ and $100 \%$, respectively, for all investigated colonic segments.

\section{DISCUSSION}

The present data indicate that MRC represents an accurate alternative to conventional colonoscopy with endoscopic biopsy for the detection and characterisation of IBD affecting the colon. Based on Tl weighted three dimensional image sets collected after administration of a water enema and intravenous paramagnetic contrast, a IBD activity score can be compiled encompassing four quantifiable criteria: colonic wall thickness, colonic wall enhancement, number of haustral folds, and number of perifocal lymph nodes. This score permitted the correct identification of 68 segments characterised as inflamed by histopathology. While three mildly and two moderately inflamed segments were falsely considered normal, there were no false positive readings on MRC.

Crohn's disease and ulcerative colitis are the most frequent specific IBD, with a prevalence of approximately 1 in $500 .^{31-33}$ Diagnostic procedures in IBD serve to validate the diagnosis and to optimise treatment. Features indicating colitis include mural thickening exceeding $3 \mathrm{~mm},{ }^{34-36}$ submucosal oedema, mesenteric fat stranding, mesenteric hypervascularity, and fibro-fatty proliferation..$^{37-39}$ At the time of initial diagnosis, endoscopy of the entire colon is considered mandatory, including multiple step biopsies. When diagnostic guidelines are followed and adequate clinical information is available,

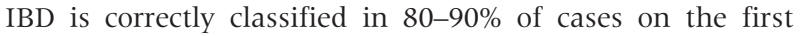
examination. $^{40-42}$

The role of colonoscopy is far less clear as it pertains to monitoring disease activity and assessing therapeutic effectiveness. The decision whether and when to perform endoscopy during disease exacerbation or following initiation of treatment remains highly individualised. When disease activity is evaluated, a distinction must be made between degree of activity, as reflected by laboratory parameters, and severity of illness, as reflected by the clinical presentation with abdominal complaints. Distinct activity indices have been shown to be useful in clinical studies although most lack objective criteria. Therefore, colonoscopy is still frequently performed and histopathology serves as the ultimate gold standard.

Despite its use as a gold standard, colonoscopy is not without limitations. Thus the view of the endoscopist is limited to the colonic lumen. Wall thickness or the presence of lymph nodes cannot be assessed. This limitation can be compensated for by the liberal use of multistep endoscopic biopsy. This procedure however is fraught with the potential for severe complications, including bowel perforation. ${ }^{43-46}$

To reduce the number of required biopsies, some authors recommend the use of endoscopic ultrasonography. Endoscopic ultrasonography represents an excellent modality for the evaluation of transmural changes of the bowel wall not seen with endoscopy alone. ${ }^{47-50}$ Soweid and colleagues ${ }^{51}$ examined 28 patients with IBD and 10 healthy subjects by means of catheter probe assisted endoluminal ultrasonography. Mean colonic wall thickness was found to be 2.2 (0.1) $\mathrm{mm}$ in healthy subjects which compares favourably with the $2 \mathrm{~mm}$ value determined with MRI in this study of 15 normal subjects. Colonic wall thickness increased to 4.1 (0.4) $\mathrm{mm}$ in patients with ulcerative colitis and $4.4(0.4) \mathrm{mm}$ in patients with Crohn's disease. Although wall thickness and layer structure correlated well with histopathological changes and clinical data, an exact quantification of disease activity was not possible. ${ }^{51-54}$ Furthermore, the technique is burdened by an invasiveness similar to colonoscopy.

Patient discomfort and the potential risks associated with endoscopic biopsy have motivated the evaluation of various radiological imaging techniques to identify and quantify IBD 
activity in the colon. In a study involving 137 IBD patients, ${ }^{54}$ abdominal ultrasonography findings were compared with the clinical activity index which includes data from urine culture, erythrocyte sedimentation rate, and $\mathrm{C}$ reactive protein values. The extent of inflammatory changes of the bowel wall detected by ultrasonography was not directly associated with an increase in the clinical activity index and laboratory parameters of inflammation.

To date, the role of CT has been mainly in identifying potential complications of IBD such as fistulas and abscesses. ${ }^{55} 56$ Assessment of the colonic wall has played a lesser role until the emergence of CT colonography (CTC) which can detect and characterise inflammatory changes affecting the colonic wall. ${ }^{37}$ To compensate for residual fluid, CTC is generally performed in the prone and supine positions. Any assessment of IBD also requires imaging prior to and following intravenous administration of iodinated contrast agents. ${ }^{58}$ The nephrotoxicity inherent in the contrast agent in conjunction with considerable exposure to ionising radiation, reflecting the need to image prone and supine as well as before and following intravenous contrast, have limited the clinical impact of CTC for monitoring IBD activity. Exposure rates easily exceeding $8 \mathrm{mSv}$ for frequently required monitoring examinations seem difficult to justify, particularly in view of the often young patients suffering from IBD. ${ }^{60-63}$ To date, a correlation between quantitative CTC parameters and histopathology in patients with IBD has yet to be provided.

Barium enema examinations represent another alternative for assessing patients suffering from IBD. Although it provides an excellent depiction of the mucosal surface, the examination is limited by radiation exposure and does not deliver exact data about the underlying inflammatory activity ${ }^{64-66} \mathrm{~A}$ functional approach to assessing inflammatory disease activity is offered by $99 \mathrm{mTc}$ hexamethyl-propylamine-oxim (HMPAO) leucocyte scintigraphy. In a trial encompassing 136 IBD patients, the technique was found to be highly sensitive and specific. ${ }^{11}$ Again, however, exposure to ionising radiation limits the clinical applicability of this examination for monitoring IBD disease activity in young patients.

Following positioning and localisation scans, MRC requires merely the acquisition of two three dimensional data acquisitions, each lasting 22 seconds. A break of more than one minute between the two acquisitions assures excellent patient compliance with breathholding instructions. Diagnostic MRC is predicated on the fulfilment of two requirements: good bowel distension and sufficient contrast between the bowel lumen and the colonic wall as well as the pathologies affecting it. Bowel distension is accomplished with rectal administration of water. ${ }^{26-28}$ The contrast between the lumen and surrounding wall is assured by the administration of a $\mathrm{Tl}$ shortening paramagnetic contrast agent. Previous studies have shown that colonic wall enhancement is maximal at around 75 seconds following contrast administration. ${ }^{26-28}$ The enhancing wall is easily delineated against the dark, cleansed, and water filled colonic lumen. The success of the examination is further determined by the contrast characteristics of the MR sequence employed. In this study, a three dimensional VIBE sequence was employed. It assures extensive $\mathrm{Tl}$ weighting with homogeneous fat suppression. The latter proved most important for the evaluation of lymph nodes in the pericolic fat. Thus the sequence permitted accurate assessment of all four quantitative parameters: wall thickness, wall enhancement, haustral folds, and perifocal lymph nodes. The combined score permitted a most accurate identification and characterisation of colonic segments affected by IBD, as confirmed by histopathological analysis.
While the underlying diagnostic criteria have been established in previous studies, ${ }^{67-70}$ this study proposes the use of a combined score to characterise IBD activity. The score is based on reference data collected in normal subjects. Herein lies a considerable weakness of the proposed methodology. Beyond the fact that the number of normal subjects and examined patients was quite limited, the absolute quantitative enhancement data underlying the relative scores are subject to considerable influence by technical details. Thus the use of a different three dimensional sequence with more or less $\mathrm{Tl}$ weighting, or the use of a contrast agent with differing relaxation properties, would severely compromise the utility of relative scores. This problem could be solved by providing standardised probes which would need to be placed in the patient's abdomen at the time of scanning. While this dependency on consistent technique is unique to the CNR parameter, patient related variations must be considered for the number of haustral folds. Although the number of folds varied little among our 15 healthy subjects, it is likely that an age dependency exists. Hence more reference data will need to be collected.

Clearly this study is burdened by other limitations. First and foremost, all patients included in the study were suffering from IBD, thereby introducing a strong reading bias. We attempted to limit the influence of this bias by focusing the analysis on colonic segments. This resulted in an excellent correlation between MRC scoring and histopathology, both with regard to identification and characterisation. All severely inflamed segments were identified as such with MRC. These results should encourage the use of MRC as an alternative to colonoscopy with biopsy in the setting of IBD monitoring and assessing treatment effectiveness. We strongly believe that the proposed MRC based activity index will prove useful for evaluating and quantifying inflammatory activity in patients with colitis.

\section{Authors' affiliations \\ W M Ajaj, T C Lauenstein, G Pelster, G Gerken, S G Ruehm, J F Debatin, S C Goehde, Department of Diagnostic and Interventional Radiology,} University Hospital Essen, Essen, Germany

Conflict of interest: None declared.

\section{REFERENCES}

1 Kiesslich R, Jung M, Galle PR, et al. Ulcerative colitis-how can endoscopic observation be improved? Dtsch Med Wochenschr 2003;128:139-41.

2 Fiocca R, Ceppa P. The diagnostic reliability of endoscopic biopsies in diagnosis colitis. J Clin Pathol 2003:56:321-2.

3 Nahon S, Bouhnik Y, Lavergne-Slove A, et al. Colonoscopy accurately predicts the anatomical severity of colonic Crohn's disease attacks: correlation with findings from colectomy specimens. Am J Gastroenterol 2002;12:3102-7.

4 Eckardt VF, Gaedertz C, Eidner C. Colonic perforation with endoscopic biopsy. Gastrointest Endosc 1997;6:560-2.

5 Cappell MS, Friedel D. The role of sigmoidoscopy and colonoscopy in the diagnosis and management of lower gastrointestinal disorders: endoscopic findings, therapy, and complications. Med Clin North Am 2002;6:1253-88.

6 Sosna J, Morrin MM, Copel L, et al. Computed tomography colonography (virtual colonoscopy): update on technique, applications, and future developments. Surg Technol Int 2003;11:102-10.

7 Ristvedt SL, McFarland EG, Weinstock LB, et al. Patient preferences for CT colonography, conventional colonoscopy, and bowel preparation. Am J Gastroenterol 2003;3:578-85.

8 Svensson MH, Svensson E, Lasson A, et al. Patient acceptance of CT colonography and conventional colonoscopy: prospective comparative study in patients with or suspected of having colorectal disease. Radiology 2002;2:337-45.

9 Thoeni RF, Gould RG. Enteroclysis and small bowel series: comparison of radiation dose and examination time. Radiology 1991;3:659-62.

10 Chernish SM, Maglinte DD, O'Connor K. Evaluation of the small intestine by enteroclysis for Crohn's disease. Am J Gastroenterol 1992;6:696-701.

11 Arndt JW, Grootscholten MI, van Hogezand RA, et al. Inflammatory bowel disease activity assessment using technetium-99m-HMPAO leukocytes. Dig Dis Sci 1997;2:387-93.

12 Charron M, Orenstein SR, Bhargava S. Detection of inflammatory bowel disease in pediatric patients with technetium-99m-HMPAO-labeled leukocytes. J Nucl Med 1994;3:451-5. 
13 Bitterling H, Rock C, Reiser M. Computed tomography in the diagnosis of inflammatory bowel disease-methodology of MSCT and clinical results. Radiologe 2003;1:17-25.

14 Wiesner W, Steinbrich W. Imaging diagnosis of inflammatory bowel disease. Ther Umsch 2003;3:137-44.

15 Jamieson DH, Shipman PJ, Israel DM, et al. Comparison of multidetector CT and barium studies of the small bowel: inflammatory bowel disease in children. AJR Am J Roentgenol 2003;5:1211-16.

16 Alves A, Panis Y, Bouhnik Y, et al. Subtotal colectomy for severe acute colitis: a 20-year experience of a tertiary care center with an aggressive and early surgical policy. Am Coll Surg 2003;3:379-85.

17 Hasegawa $H$, Watanabe $M$, Nishibori $H$, et al. Laparoscopic surgery for recurrent Crohn's disease. Br J Surg 2003;8:970-3.

18 Schunk K, Kern A, Oberholzer K, et al. Hydro-MRI in Crohn's disease: appraisal of disease activity. Invest Radiol 2000;7:431-7.

19 Giovagnoni A, Fabbri A, Maccioni F. Oral contrast agents in MRI of the gastrointestinal tract. Abdom Imaging 2002;4:367-75.

20 Kettritz U, Isaacs K, Warshaver DM, et al. Crohn's disease. Pilot study comparing MRI of the abdomen with clinical evaluation. J Clin Gastroenterol 1995; 3:249-53.

21 Madsen SM, Thomsen HS, Munkholm P, et al. Active Crohn's disease and ulcerative colitis evaluated by low-field magnetic resonance imaging. Scand J Gastroenterol 1998;11:1193-200.

22 Schunk K, Kern A, Heussel CP, et al. Assessment of inflammatory activity in Crohnis disease with hydro-MRI. Rofo Fortschr Geb Rontgenstr Neuen Bildgeb Verfahr 2000;2:153-60

23 Koh DM, Miao Y, Chinn RJ, et al. MR imaging evaluation of the activity of Crohn's disease. AJR Am J Roentgenol 2001:6:1325-32.

24 Maglinte DD, Gourtsoyiannis N, Rex D, et al. Classification of small bowel Crohn's subtypes based on multimodality imaging. Radiol Clin North Am 2003;2:285-303.

25 Pauls S, Kratzer W, Rieber A, et al. Quantifying the inflammatory activity in Crohn's disease using CE dynamic MRI. Rofo Fortschr Geb Rontgenstr Neven Bildgeb Verfahr 2003;8:1093-9.

26 Lauenstein TC, Herborn CU, Vogt FM, et al. Dark lumen MR-colonography: initial experience. Rofo Fortschr Geb Rontgenstr Neven Bildgeb Verfahr $2001 ; 9: 785-9$.

27 Lavenstein TC, Goehde SC, Ruehm SG, et al. MR colonography with bariumbased fecal tagging: initial clinical experience. Radiology 2002;1:248-54.

28 Lauenstein T, Holtmann G, Schoenfelder D, et al. MR colonography without colonic cleansing: a new strategy to improve patient acceptance. AJR Am J Roentgenol 2001:4:823-7.

29 Thomeer M, Bielen D, Vanbeckevoort D, et al. Patient acceptance for CT colonography: what is the real issue? Eur Radiol 2002;12:1410-15

30 Angtuaco TL, Banaad-Omiotek GD, Howden CW. Differing attitudes toward virtual and conventional colonoscopy for colorectal cancer screening: surveys among primary care physicians and potential patients. Am J Gastroenterol 2001;96:887-93.

31 Ochsenkuhn T, Sackmann M, Goke B. Inflammatory bowel diseases (IBD): critical discussion of etiology, pathogenesis, diagnostics, and therapy. Radiologe 2003;1:1-8.

32 Schneider W. Epidemiology of chronic inflammatory intestinal diseases. Z Gesamte Inn Med 1981;3:228-30.

33 Karlinger K, Gyorke T, Mako E, et al. The epidemiology and the pathogenesis of inflammatory bowel disease. Eur J Radiol 2000;3:154-67.

34 Born C, Nagel B, Leinsinger G, et al. MRI with oral filling in patients with chronic inflammatory bowel diseases. Radiologe 2003;1:34-42.

35 Valette PJ, Rioux M, Pilleul F, et al. Ultrasonography of chronic inflammatory bowel diseases. Eur Radiol 2001;10:1859-66.

36 Reimund JM, Jung-Chaigneau E, Chamouard P, et al. Diagnostic value of high resolution sonography in Crohn's disease and ulcerative colitis. Gastroenterol Clin Biol 1999;7:740-6.

37 Tarian Z, Toth G, Gyorke T, et al. Ultrasound in Crohn's disease of the small bowel. Eur J Radiol 2000;3:176-82.

38 Tarian Z, Zagoni T, Gyorke T, et al. Spiral CT colonography in inflammatory bowel disease. Eur J Radiol 2000;3:193-8.

$39 \mathrm{Lim} \mathrm{JH}, \mathrm{Ko}$ YT, Lee DH, et al. Sonography of inflammatory bowel disease: findings and value in differential diagnosis. AJR Am J Roentgenol 1994;2:343-7

40 Dafnis G, Granath F, Pahlman L, et al. The impact of endoscopists' experience and learning curves and interendoscopist variation on colonoscopy completion rates. Endoscopy 2001;6:511-17.
41 Spinzi G, Belloni G, Martegani A, et al. Computed tomographic colonography and conventional colonoscopy for colon diseases: a prospective, blinded study. Am J Gastroenterol 2001;2:394-400.

42 Meyer G, Merkle R, Schinkel S, et al. Postoperative endoscopy for the diagnosis and therapy of complications. Chirurg 2002;1:9-21.

43 Gonzalez-Ramirez A, Avila S, Lopez-Roses L, et al. Small bowel obstruction and perforation after colonoscopy. Endoscopy 2003;2:192.

44 Rodriguez SA, Ormseth E, Tsuchida A. Bowel perforation with the variable stiffness colonoscope. Gastrointest Endosc 2003;2:271-3.

45 Eckardt VF, Gaedertz C, Eidner C. Colonic perforation with endoscopic biopsy. Gastrointest Endosc 1997;6:560-2.

46 Hall C, Dorricott NJ, Donovan IA, et al. Colon perforation during colonoscopy: surgical versus conservative management. $\mathrm{Br} J$ Surg 1991;5:542-4.

47 Lew RJ, Ginsberg GG. The role of endoscopic ultrasound in inflammatory bowel disease. Gastrointest Endosc Clin N Am 2002;3:561-71.

48 Higaki S, Nohara H, Saitoh Y, et al. Increased rectal wall thickness may predict relapse in ulcerative colitis: a pilot follow-up study by ultrasonographic colonoscopy. Endoscopy 2002;3:212-19.

49 Gast $\mathbf{P}$, Belaiche J. Rectal endosonography in inflammatory bowel disease: differential diagnosis and prediction of remission. Endoscopy 1999:2:158-66.

50 Cho E, Mochizuki N, Ashihara T, et al. Endoscopic ultrasonography in the evaluation of inflammatory bowel disease. Endoscopy 1998;1:94-6.

51 Soweid AM, Chak A, Katz JA, et al. Catheter probe assisted endoluminal US in inflammatory bowel disease. Gastrointest Endosc 1999;1:41-6.

52 Bartram Cl, Herlinger $\mathrm{H}$. Bowel wall thickness as a differentiating feature between ulcerative colitis and Crohn's disease of the colon. Clin Radiol 1979;1:15-19

53 Rasmussen SN, Riis P. Rectal wall thickness measured by ultrasound in chronic inflammatory diseases of the colon. Scand J Gastroenterol 1985:1:109-14.

54 Mayer D, Reinshagen M, Mason RA, et al. Sonographic measurement of thickened bowel wall segments as a quantitative parameter for activity in inflammatory bowel disease. Z Gastroenterol 2000;4:295-300.

55 Maconi G Sampietro GM, Parente F, et al. Contrast radiology, computed tomography and ultrasonography in detecting internal fistulas and intraabdominal abscesses in Crohn's disease: a prospective comparative study. Am J Gastroenterol 2003;7:1545-55.

56 Boudiaf $M$, Soyer P, Terem C, et al. Abdominal complications of Crohn's disease: CT features. J Radiol 2000;1:11-18.

57 Taylor SA, Halligan S, Bartram Cl. CT colonography: methods, pathology and piffalls. Clin Radiol 2003;3:179-90.

58 Vogl TJ, Luboldt W, Herzog CH, et al. Contrast-enhanced multislice CT in detection and evaluation of abdominal neoplasms. Radiologe 2002;8:646-54.

59 Neri E, Giusti P, Battolla L, et al. Colorectal cancer: role of CT colonography in preoperative evaluation after incomplete colonoscopy. Radiology 2002;3:615-19.

60 Thoeni RF, Gould RG. Enteroclysis and small bowel series: comparison of radiation dose and examination time. Radiology 1991;3:659-62.

61 van Gelder RE, Venema HW, Serlie IW, et al. CT colonography at different radiation dose levels: feasibility of dose reduction. Radiology 2002;1:25-33.

62 Hara AK, Johnson CD, Reed JE, et al. Reducing data size and radiation dose for CT colonography. AJR Am J Roentgenol 1997;5:1181-4.

63 Scholmerich J. Inflammatory bowel disease. Endoscopy 2003;2:164-70.

64 Durdey P, Weston PM, Williams NS. Colonoscopy or barium enema as initial investigation of colonic disease. Lancet 1987:2:549-51.

65 Freeny PC. Crohn's disease and ulcerative colitis. Evaluation with doublecontrast barium examination and endoscopy. Postgrad Med 1986;3:139-52.

66 Kelvin FM, Oddson TA, Rice RP, et al. Double contrast barium enema in Crohn's disease and ulcerative colitis. AJR Am J Roentgenol 1978:2:207-13.

67 D'Arienzo A, Scaglione G, Bennato R, et al. The prognostic value, in active ulcerative colitis, of an increased intensity of colonic perivisceral fat signal on magnetic resonance imaging with ferumoxil. Am J Gastroenterol 2001;2:481-6.

68 Sardanelli F, de Cicco E, Renzetti P, et al. Double-contrast magnetic resonance examination of ulcerative colitis. Eur Radiol 1999;5:875-9.

69 Schunk K. Small bowel magnetic resonance imaging for inflammatory bowel disease. Top Magn Reson Imaging 2002;6:409-25.

70 Wiesner W, Steinbrich W. Imaging diagnosis of inflammatory bowel disease. Ther Umsch 2003;3:137-44. 